\title{
Comparison of Sirolimus and Colchicine Treatment on the Development of Peritoneal Fibrozis in Rats Having Peritoneal Dialysis
}

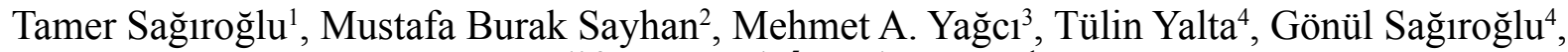 \\ Elif Çopuroğlu ${ }^{5}$, Serhat Oğuz ${ }^{1}$
}

\footnotetext{
${ }^{1}$ Deptartment of General Surgery, Trakya University Faculty of Medicine, Edirne, Turkey

${ }^{2}$ Deparment of Emergency Medicine, Trakya University Faculty of Medicine, Edirne, Turkey

${ }^{3}$ Department of General Surgery, İnönü University Faculty of Medicine, Malatya, Turkey

${ }^{4}$ Department of Pathology, Trakya University Faculty of Medicine, Edirne, Turkey

${ }^{5}$ Department of Anesthesiology, Trakya University Faculty of Medicine, Edirne, Turkey
}

Background: Continuous ambulatory peritoneal dialysis is a successful treatment modality for patients with end-stage renal disease. Peritoneal fibrosis (PF) is the most critical complication of long-term peritoneal dialysis (PD).

Aims: In our study, we aimed to compare the effects of colchicine and sirolimus on PF induced by hypertonic peritoneal dialysis solutions in rats.

Study Design: Animal experiment.

Methods: Twenty-four rats were randomly divided into three groups. The control group received an intraperitoneal injection (ip) of saline. The sirolimus group received the $\mathrm{PD}$ solution, plus $1.0 \mathrm{mg} / \mathrm{kg} /$ day Rapamune ${ }^{\circledR}$. The colchicine group received the PD solution ip plus $1.0 \mathrm{mg} / \mathrm{kg} /$ day of colchicine. Blood samples were taken to measure the serum levels of VEGF, TGF- $\beta$, and TNF- $\alpha$. Peritoneal tissue samples were taken for histopathological evaluation.

Results: TGF- $\beta$ and TNF- $\alpha$ values in the sirolimus group were found to be statistically significantly lower than in the control and colchicine groups, but the differences between the control and colchicine groups were not statistically significant. No statistically significant differences were found between the groups regarding the VEGF values. Vascular neogenesis and peritoneal thickness were compared; the values in the sirolimus group were statistically reduced compared to the values in the control group. Mild fibrosis developed in $75 \%$ of all animals in the sirolimus group; there was no moderate or severe fibrosis observed. Fibrosis developed to varying degrees in $100 \%$ of the animals in the control and colchicine groups.

Conclusion: The present study demonstrates that sirolimus might be beneficial for preventing or delaying the progression of PF and neoangiogenesis. These alterations in the peritoneal membrane may be connected with reduced TNF- $\alpha$ and TGF- $\beta$ levels.

Keywords: Colchicine, peritoneal dialysis, peritoneal fibrosis, sirolimus
Peritoneal fibrosis (PF) is the most critical complication of long-term continuous ambulatory peritoneal dialysis (CAPD) (1). The prevalence of PF ranges from 0 to $4.4 \%$ in some studies and from 0.7 to $2.8 \%$ in registries. The preva- lence exceeds $19 \%$ in patients treated for more than eight years $(2,3)$.

Degeneration of peritoneal membrane function remains a cardinal factor causing a modality change in a significant

This study was presented at the $6^{\text {th }}$ Surgical Research, 8-10 December 2011, Ankara, Turkey.

Address for Correspondence: Dr. Tamer Sağıroğlu, Department of General Surgery, Trakya University Faculty of Medicine, Edirne, Turkey Phone: +90 5322848934 e-mail: tamersagiroglu@gmail.com

Received: 24.03.2014 Accepted: 04.11.2014 • DOI: 10.5152/balkanmedj.2015.15183

Available at www.balkanmedicaljournal.org 
number of patients on CAPD. In long-term patients undergoing CAPD, many changes to the peritoneum occur, including interstitial fibrosis, denudation of mesothelial cells, vascular alterations that mimic diabetic microangiopathy, vasodilatation, and neovascularization (1).

A limited number of in vivo studies has analyzed the effects of different glucose concentrations on transforming growth factor $\beta$ (TGF- $\beta$ ) and tumor necrosis factor-alpha (TNF- $\alpha$ ) release from peritoneal or peripheral blood macrophages, monocytes, and mesothelial cells (4). TGF- $\beta$, which is a wellknown growth factor in human disease, has been found to increase fibrotic injury during peritonitis (5). Increasing evidence has shown that TGF- $\beta$ is a key mediator of experimental and human PF associated with CAPD (6). Douvdevani et al. (7) studied the in vitro effect of dialysis fluid on the release of TNF- $\alpha$ by peritoneal macrophages, human peritoneal mesothelial cells (HPMC) and peripheral blood mononuclear cells (PBMC).

A number of clinicians do not know how the development of $\mathrm{PF}$ in CAPD patients can be prevented. In recent years, some drugs have been used to restrict the propagation of HPMC or matrix formation, which may be beneficial in preventing or delaying the progression of PF (1).

Colchicine is an effective anti-inflammatory agent. It has been shown to interfere with the interaction of neutrophils and the vascular endothelium by abrogating their binding to adhesion molecules. Colchicine decreases the generation of TNF- $\alpha$ by macrophages and its receptors on endothelial cells (1).

Sirolimus, the newest of the antifungal macrolide antibiotics, has documented potent immunosuppressive activity in the mouse heart and kidney (8). Everolimus, a derivative of sirolimus, has beneficial effects in renal failure, inflammation and fibrosis. Everolimus may have curative value in the management of PF (9).

There has been no study in the literature comparing the effects of sirolimus and colchicine on the development of peritoneal fibrosis. In the present study, we aimed to compare the effects of colchicine and sirolimus on peritoneal alterations induced by a hypertonic peritoneal dialysis solution in rats.

\section{MATERIALS AND METHODS}

Approval was provided for all the procedures and protocols used in this experimental study from the Animal Ethics Committee.

\section{Animals}

Twenty-four adult male Sprague Dawley rats, weighing $280 \pm 20 \mathrm{~g}$ and averaging 24 weeks old, were included in our study. Rats having the same physiological and biological prop- erties were provided by the Experimental Research Center of the Medical Faculty. All animals were kept in stainless steel cages and standardized laboratory conditions of temperature $\left(22 \pm 2^{\circ} \mathrm{C}\right)$, relative humidity $(55-60 \%)$, and a 12 -h dark/light cycle. They were fed with standard rat chow and tap water ad libitum. All animals were treated humanely according to the criteria outlined in the "Guide for the Care and Use of Laboratory Animals" prepared by the National Academy of Sciences and published by the National Institutes of Health.

\section{Experimental groups}

The 234 rats were randomly divided into three groups and eight rats were included in each of the following groups $(n=8)$. The control group received an intraperitoneal (ip) injection of saline $(20 \mathrm{ml} / \mathrm{kg} \mathrm{BW})$. The sirolimus group received $20 \mathrm{ml} /$ kg BW of a 3.86\% PD solution ip plus Rapamune ${ }^{\circledR}$ (WyethAyerst Research Laboratories, Philadelphia, PA) at a dose of $1.0 \mathrm{mg} / \mathrm{kg} /$ day (10). The colchicine group received $20 \mathrm{ml} / \mathrm{kg}$ BW of a $3.86 \%$ PD solution ip plus $1.0 \mathrm{mg} / \mathrm{kg} /$ day BW of colchicine (Sigma) in saline (1).

\section{Experimental procedures}

All procedures were performed under a heat lamp and the body temperature of the rats was kept at $35-36^{\circ} \mathrm{C}$ constantly. Food withdrawn 12 hours before anesthesia, but rats were released for water two hours before anesthesia to apply the catheter. The animals were anesthetized with $90 \mathrm{mg} / \mathrm{kg}$ body weight ketamine hydrochloride (Ketalar flk; Pfizer Ltd. Company, İstanbul, Turkey) plus $10 \mathrm{mg} / \mathrm{kg}$ body weight xylazine (Rompun; Bayer, Turkish Chemistry Industry and Limited Company, İstanbul, Turkey) intramuscularly. The abdomen and neck were shaved and disinfected with $10 \%$ povidone iodine solution before the surgical intervention. A peritoneal dialysis catheter made from titanium/silicone device (Rat-oPort, MTINC, 7IS; Access Technologies, Norfolk Medical, Skokie, Illinois, USA) was inserted into the intraabdominal cavity through a $3 \mathrm{~cm}$ midline abdominal incision in animals fixed in a supine position. Another part of the catheter was implanted subcutaneously in the neck through a $2 \mathrm{~cm}$ incision to prevent catheter gnawing by the rats under sterile conditions (11). The operation was finished by closing the midline incision, fascia and skin separately using continuous absorbable 4/0 polyglactin sutures (Vicryl; Ethicon, Johnson \& Johnson Company USA) and 3/0 atraumatic silk sutures (Sterisilk ${ }^{\circledR}$; SSM, İstanbul, Turkey).

Following surgery, all the rats were separated into groups and placed in different special cages to prevent catheter gnawing by other rats under controlled temperature, wetness, and lighting conditions. After the experimental period started, peritoneal healing was allowed for 1 week after catheter insertion by a daily infusion of $1 \mathrm{~mL}$ heparinized saline (5 IU/ 
a

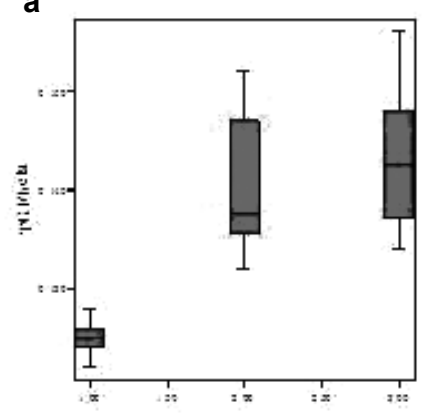

b

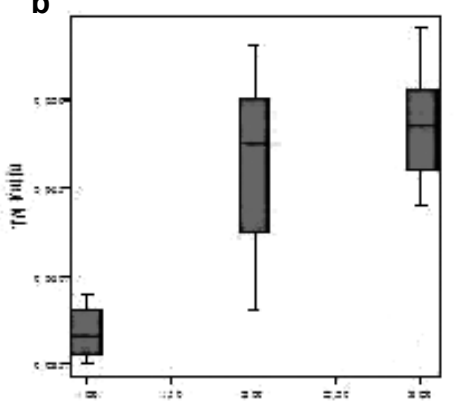

Experimenta groups

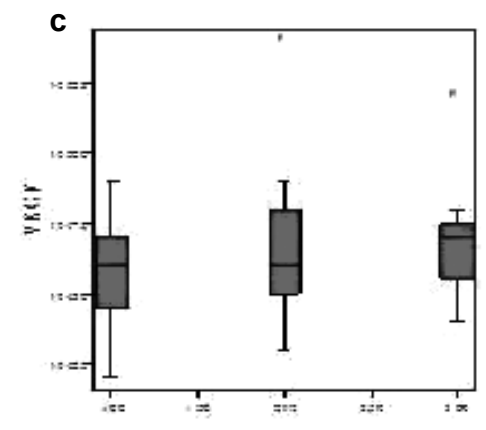

FIG. 1. a-c. Serum TGF- $\beta$ (a), TNF- $\alpha$ (b), VEGF (c) measurement values in experimental groups.

TABLE 1. Serum levels of biochemical parameter

\begin{tabular}{ccccc}
\hline & $\begin{array}{c}\text { Sirolimus } \\
\text { group }\end{array}$ & $\begin{array}{c}\text { Control } \\
\text { group }\end{array}$ & $\begin{array}{c}\text { Colchicine } \\
\text { group }\end{array}$ & $\mathrm{p}^{\mathrm{a}}$ \\
\hline TGF- $\beta$ & $0.125 \pm 0.002$ & $0.140 \pm 0.007^{\mathrm{b}}$ & $0.143 \pm 0.007^{\mathrm{b}}$ & $<0.001$ \\
$\mathrm{TNF}-\alpha$ & $0.0367 \pm 0.001$ & $0.046 \pm 0.005^{\mathrm{b}}$ & $0.048 \pm 0.003^{\mathrm{b}}$ & $<0.001$ \\
VEGF & $0.0457 \pm 0.002$ & $0.046 \pm 0.003$ & $0.047 \pm 0.002$ & 0.601 \\
\hline
\end{tabular}

${ }^{a} A N O V A$, bost hoc analysis with Scheffe test

$\mathrm{mL} \mathrm{NaCl} 0.9 \%$ ). All rats received a daily infusion of $60 \mathrm{ml} / \mathrm{kg}$ body weight (BW) of $3.86 \%$ glucose-containing dialysis solution (Baxter SA, Castlebar, Ireland) via the Rat-o-Port (11).

The animals were put down with a high-dose injection of thiopental sodium on the twenty-eight day. After opening the abdominal cavity, samples from the peritoneal tissue were examined for the presence of fibrosis and the number of vessels. Blood samples $(5-7 \mathrm{~mL})$ were taken by cardiac puncture from all rats using sterile instruments under aseptic conditions to measure serum levels of VEGF, TGF- $\beta$, and TNF- $\alpha$. The same surgeon conducted all operations with the same technique.

\section{Histopathology}

All of the peritoneal tissue samples were fixed in $10 \%$ neutral buffered formalin solution for histopathological evaluation after sacrificing the animals. Later, they were embedded in paraffin, and sections at a thickness of $5 \mu \mathrm{m}$ were prepared and stained with hematoxylin-eosin (HE) and Masson's trichrome stains. Immunohistochemical stains were used to detect the expression of VEGF (VEGF-Ab-1, polyclonal, Neomarkers, Fremont, USA) and CD31 (mouse monoclonal, Neomarkers, Fremont, USA). For each sample, the peritoneal membrane thickness (in mm) was measured at 10 randomly chosen sites using computer aided histomorphometry device in HE-stained sections (12). The amount of fibrosis was graded as $0=$ normal presence of fibrous tissue, $1=$ mild excess, $2=$ moderate, and $3=$ severe in Masson's trichrome stained sections (3). For each peritoneal tissue section, the number of vessels was counted in ten random fields at 100x magnification in CD31 stained sections (13). For each sample, the number of VEGF-positive cells was counted in 10 random field at 100x magnification in VEGF stained sections (14). Then, the specimens were examined under a light microscope. Histopathological examinations were performed by a pathologist who was blinded to the study design, and photographs were taken with a Zeiss Axioplan 2 microscope and a Nikon E600 camera.

\section{Statistical analyses}

Univariate statistical analyses were performed using Fisher's exact test (c2) for categorical variables. Numerical values were expressed as mean \pm standard deviation (SD). Whether the measured values correspond to the normal distribution was investigated using the one-sample Kolmogorov-Smirnov test. Parametric variables among groups were compared using one-way analysis of variance (ANOVA) and post hoc analysis was done with the Scheffe test. Statistical significance was set at $p<0.05$. All analyses were performed with the Statistical Package for Social Sciences version 15.0 (SPSS, Chicago, IL).

\section{RESULTS}

The values measured during serum parameter analysis and the histopathological results were compared between the three independent groups in our study.

TGF- $\beta$ values in the sirolimus group were found to be statistically significantly lower than in the control and colchicine groups $(\mathrm{p}<0.001)$, but the difference between the control and colchicine groups was not statistically significant $(\mathrm{p}=0.705)$ (Table 1) (Figure 1a).

TNF- $\alpha$ values in the sirolimus group were found to be statistically significantly lower than in the control and colchicine groups $(\mathrm{p}<0.001)$, but the difference between the control and colchicine groups was not statistically significant $(\mathrm{p}=0.503)$ (Table 1) (Figure 1b). 
TABLE 2. Histopathological values

\begin{tabular}{|c|c|c|c|c|}
\hline & Sirolimus group & Control group & Colchicine group & $\mathrm{p}$ \\
\hline Blood vessels (n) & $25.8750 \pm 14.21707$ & $68.1250 \pm 26.68032$ & $54.8750 \pm 36,56477$ & 0.017 \\
\hline Peritoneal thickness (mm) & $0.0827 \pm 0.036138$ & $0.2120 \pm 0.8723$ & $0.1382 \pm 0.3925$ & 0.001 \\
\hline
\end{tabular}

TABLE 3. Development of fibrozis

\begin{tabular}{|c|c|c|c|c|c|}
\hline & Nofibrozis & Mild & Modarate & Severe & Total \\
\hline Sirolimus group & $2(25 \%)$ & $6(75 \%)$ & - & - & $8(100 \%)$ \\
\hline Control group & - & $3(37.5 \%)$ & $2(25 \%)$ & $3(37.5 \%)$ & $8(100 \%)$ \\
\hline Colchicine group & - & $3(37.5 \%)$ & $5(62.5 \%)$ & - & $8(100 \%)$ \\
\hline
\end{tabular}

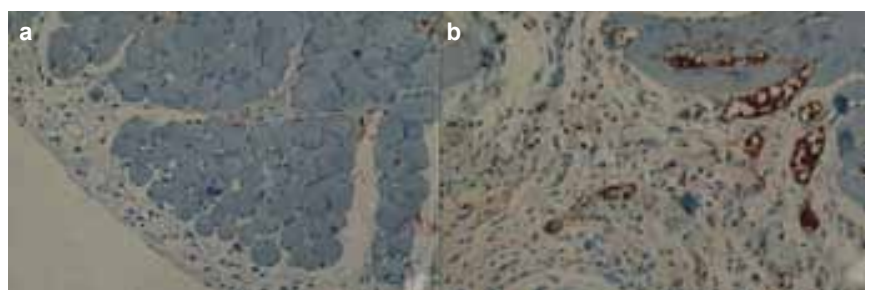

FIG. 2. a, b. The number of vessels in control group (a) and sirolimus group (b) in the sections stained immunohistochemically with CD 31

No statistically significant differences were found between the groups regarding the VEGF values $(\mathrm{p}=0.601)$ (Table 1) (Figure 1c). Serum values are presented in Table 1, according to the groups, in detail.

As a result of the histopathological evaluations, when the obtained values for the newly formed blood vessels (vascular neogenesis) were compared, the values in the sirolimus group were statistically significantly reduced compared to the values in the control group ( $\mathrm{p}=0.017$ ), (Figure $2 \mathrm{a}, 2 \mathrm{~b}$ ). The differences between the control group and colchicine group and between the colchicine group and the sirolimus group were not statistically significant. As a result of the histopathological measurements of peritoneal thickness, the values in the sirolimus group were statistically significantly reduced compared to the values in the control group ( $\mathrm{p}=0.001$ ), (Figure $3 \mathrm{a}, \mathrm{b}$ ). The results of the histopathological evaluations according to the groups are presented in Table 2, in detail.

When the development of fibrosis between the groups was assessed, mild fibrosis was observed in $75 \%$ of the rats in the sirolimus group, with no moderate or severe fibrosis. Fibrosis developed to varying degrees in $100 \%$ of the rats in the control and colchicine groups. The development of fibrosis according to the groups is detailed in Table 3 .

\section{DISCUSSION}

Continuous ambulatory peritoneal dialysis is an essential and is used by $>100,000$ patients with ESRD worldwide, accounting for approximately 10 to $15 \%$ of the dialysis population (15). A significant handicap to successful long-term CAPD is

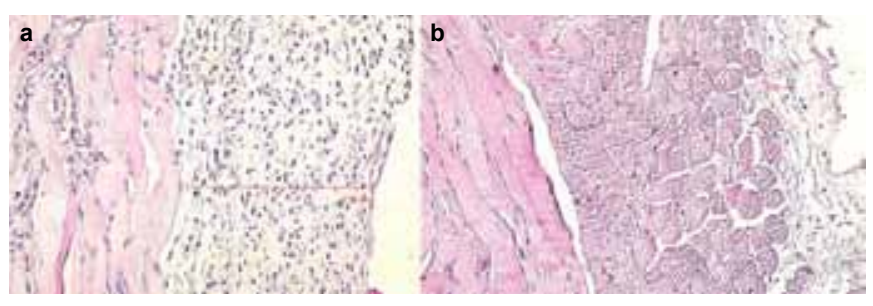

FIG. 3. a, b. Peritoneal membrane thickness measured in control group (a) and sirolimus group (b) with hematoxylin-eosin dye

the harmful functional alterations that occur in the peritoneal membrane after exposure to dialysis solutions which include a high glucose load (16). These alterations, which occur primarily in the visceral peritoneum, include progressive fibrosis, neoangiogenesis, an increase in the submesothelial thickness and blood vessel deformation (17). These pathological findings are associated with a loss of ultrafiltration and increased mortality and morbidity (16). The cause of PF is unclear. A high concentration of blood glucose alone induces fibrogenic growth factors in peritoneal mesothelial cells in culture (17). TGF- $\beta$ is widely known as a major mediator of fibrosis. In addition, previous studies have shown that increased expression of TGF- $\beta$ is related to the extent of PF (6). In vitro studies have shown the production of TGF- $\beta$ induced by high glucose concentrations in human peritoneal mesothelial cells (18).

Many authors have attempted to prevent peritoneal fibrosis with of pharmacological interventions using in vivo experimental rat models (16). A number of agents can reduce both angiogenesis and fibrosis. Colchicine is one of these agents. Colchicine is a tricyclic alkaloid agent, and its analgesic and anti-inflammatory effects have been linked to its ability to bind with tubulin, inhibiting neutrophil motility and activity, leading to a net anti-inflammatory effect. The essential antiinflammatory mechanism of colchicine is via the inhibition of granulocyte migration into the inflamed area, thereby inhibiting proliferation and affecting cells with high turnover (19).

There have been many studies showing that colchicine prevents tissue fibrosis and sclerosis. Previous studies have shown that colchicine is effective in decreasing hepatic fibrosis in primary biliary cirrhosis $(20,21)$. Peters et al. (22) also 
observed that idiopathic pulmonary fibrosis can be rescued by colchicine.

Sayarloglu et al. (1) investigated the effect of colchicine on peritoneal alterations induced by hypertonic peritoneal dialysis solutions in an experimental model. They found that blood TGF- $\beta$ levels were significantly lower in the control group compared with the colchicine group, but they could not find significant changes differences between groups in terms of characteristic findings of peritoneal fibrosis in the histological evaluation. Sayarlioglu and colleagues concluded that colchicine could not prevent peritoneal incompatibility. There were no meaningful differences between the control and colchicine groups regarding peritoneal thickness and neoangiogenesis, or TGF- $\beta$ and TNF- $\alpha$ values in our study.

Peritoneal fibrosis occurs as a result of peritoneal damage after peritoneal dialysis. Mild, moderate and severe degrees of peritoneal fibrosis developed in the untreated group; mild and moderate degrees of peritoneal fibrosis developed in the colchicine group, while severe degrees of peritoneal fibrosis were prevented. It seems that the positive effect of colchicine was not literally in the prevention of peritoneal fibrosis. The peritoneal damage that occurred after peritoneal fibrosis in our study has similar features to those shown by Sayarlioglu et al. (1). We think that efficient new drugs as an alternative to colchicine should be investigated.

Sirolimus is a potent advanced immunosuppressive drug that is approved for clinical use to prevent rejection in solid organ transplantation (23-26). In addition, new experimental studies have proposed that sirolimus may reduce peritoneal fibrosis and neoangiogenesis, attenuate disease progression, and may be used as an antiproliferative drug $(25,26)$. The antifibrotic and antiproliferative effects of sirolimus have been recently reported in several animal models of chronic renal disease, including chronic glomerulosclerosis, diabetic nephropathy, and tubulointerstitial fibrosis $(25,27,28)$.

Peker et al. (29) found that immunosuppressive drugs have a significant effect on histopathological findings of peritoneal adhesion. Also, fibrosis and vascular proliferation were significantly decreased in all experimental groups.

In our study, peritoneal thickness and vessel counts were reduced in the sirolimus group compared to both the control and in colchicine groups. Similarly, as well as the histopathological examinations, the measurements of TGF- $\beta$ and TNF- $\alpha$ in the control and in colchicine groups were significantly decreased compared to the sirolimus group. Sirolimus coordinates the rate of cell growth, differentiation, proliferation, migration, and protein synthesis in a number of cell types, including epithelial cells, vascular smooth muscle, and fibroblasts (28). In the same way, sirolimus prevents extracellular matrix deposition in chronic disease progression $(25,30)$.
When peritoneal injury was evaluated as an indicator of the development of peritoneal fibrosis, treatment with colchicine inhibited the development of peritoneal fibrosis, as moderate or severe peritoneal fibrosis did not develop in the sirolimus group. There was a superior effect of sirolimus over colchicine in the prevention of increased thickness of the peritoneum, in the number of vessels, and in the development of peritoneal fibrosis.

In conclusion, the present study demonstrates that sirolimus might be beneficial in preventing or delaying the progression of $\mathrm{PF}$ and neoangiogenesis. These alterations to the peritoneal membrane may be connected with reduced TNF- $\alpha$ and TGF- $\beta$ levels. A number of studies providing further support are required to determine the role of sirolimus in the pathogenesis and treatment of peritoneal fibrosis induced by high glucose concentration dialysis solution.

In this study, serum urea, creatinine, $\mathrm{K}, \mathrm{Na}, \mathrm{Cl}$ values, $\mathrm{D} / \mathrm{P}$ creatinine, D/P urea, D/P glucose, and the filtration levels were not examined or measured. We counted the numbers of new vessels instead of quantifying vasculopathy; for this reason, the Williams score was not used.

Ethics Committee Approval: Ethics committee approval was received for this study.

\section{Informed Consent: N/A.}

Peer-review: Externally peer-reviewed.

Author contributions: Concept - T.S., M.B.S.; Design - T.S., M.B.S., S.O.; Supervision - M.A.Y., T.S., M.B.S.; Resource - T.S., G.S., T.Y., Materials - G.S., T.S., E.C.; Data Collection\&or Processing - T.Y., T.S., G.S. Analysis\&/or Interpretation - M.A.Y., T.Y., G.S., E.C.; Literature Search - M.B.S., S.O.;Writing - M.B.S., T.S., E.C.; Critical Reviews - E.C., M.B.S., S.O.

Acknowledgments: The authors thank Gülce Sari and Esin Seçgin Sayhan for their supports.

Conflict of Interest: No conflict of interest was declared by the authors.

Financial Disclosure: The authors declared that this study received no financial support.

\section{REFERENCES}

1. Sayarlioglu H, Dogan E, Erkoc R, Ozbek H, Bayram I, Sayarlioglu M, et al. The effect of colchicine on the peritoneal membrane. Ren Fail 2006;28:69-75. [CrossRef]

2. Kawaguchi Y, Kawanishi H, Mujais S, Topley N, Oreopoulos DG. Encapsulating peritoneal sclerosis: definition, etiology, 
diagnosis and treatment. International Society for Peritoneal Dialysis Ad Hoc Committee on Ultrafiltration Management in Peritoneal Dialysis. Perit Dial Int 2000;20:43-55.

3. Van Westrhenen R, Aten J, Hajji N, de Boer OJ, Kunne C, de Waart $\mathrm{DR}$, et al. Cyclosporin A induces peritoneal fibrosis and angiogenesis during chronic peritoneal exposure to a glucose-based, lactatebuffered dialysis solution in the rat. Blood Purif 2007;25:466-72. [CrossRef]

4. Sayarlioglu H, Topal C, Sayarlioglu M, Dulger H, Dogan E, Erkoc R. Effect of glucose concentration on peritoneal inflammatory cytokines in continuous ambulatory peritoneal dialysis patients. Mediators Inflamm 2004;13:119-21. [CrossRef]

5. Lin CY, Chen WP, Yang LY, Chen A, Huang TP. Persistent transforming growth factor beta 1 expression may predict peritoneal fibrosis in CAPD patients with frequent peritonitis occurrence. Am J Nephrol 1998;18:513-9. [CrossRef]

6. Margetts PJ, Oh KH, Kolb M. Transforming growth factor-beta: importance in long-term peritoneal membrane changes. Perit Dial Int 2005;25:15-7.

7. Douvdevani A, Rapoport J, Konforti A, Zlotnik M, Chaimovitz C. The effect of peritoneal dialysis fluid on the release of IL-1 beta and TNF alpha by macrophages/monocytes. Perit Dial Int 1993;13:112-7.

8. Fealy MJ, Umansky WS, Bickel KD, Nino JJ, Morris RE, Press $\mathrm{BH}$. Efficacy of rapamycin and FK 506 in prolonging rat hind limb allograft survival. Ann Surg 1994;219:88-93. [CrossRef]

9. Duman S, Bozkurt D, Sipahi S, Sezak M, Ozkan S, Ertilav M, et al. Effects of everolimus as an antiproliferative agent on regression of encapsulating peritoneal sclerosis in a rat model. $A d v$ Perit Dial 2008;24:104-10.

10. Roqué M, Reis ED, Cordon-Cardo C, Taubman MB, Fallon JT, Fuster V, et al. Effect of p27 deficiency and rapamycin on intimal hyperplasia: in vivo and in vitro studies using a p27 knockout mouse model. Lab Invest 2001;81:895-903. [CrossRef]

11. van Westrhenen R, Aten J, Aberra M, Dragt CA, Deira G, Krediet RT. Effects of inhibition of the polyol pathway during chronic peritoneal exposure to a dialysis solution. Perit Dial Int 2005;25 Suppl 3:18-21.

12. Kalk P, Rückert M, Godes M, von Websky K, Relle K, Neumayer HH, Hocher B, Morgera S. Does endothelin B receptor deficiency ameliorate the induction of peritoneal fibrosis in experimental peritoneal dialysis? Nephrol Dial Transplant 2010;25:1474-8. [CrossRef]

13. Yuan J, Fang W, Ni Z, Dai H, Lin A, Cao L, et al. Peritoneal morphologic changes in a peritoneal dialysis rat model correlate with angiopoietin/Tie-2. Pediatr Nephrol 2009;24:163-70. [CrossRef]

14. Komatsu H, Uchiyama K, Tsuchida M, Isoyama N, Matsumura M, Hara T, et al. Development of a peritoneal sclerosis rat model using a continuous-infusion pump. Perit Dial Int 2008;28:641-7.

15. Grassmann A, Gioberge S, Moeller S, Brown G. ESRD patients in 2004: global overview of patient numbers, treatment modalities and associated trends. Nephrol Dial Transplant 2005;20:2587-93. [CrossRef]
16. Devuyst O, Margetts PJ, Topley N. The pathophysiology of the peritoneal membrane. J Am Soc Nephrol 2010;21:1077-85. [CrossRef]

17. Sampimon DE, Kolesnyk I, Korte MR, Fieren MW, Struijk DG, Krediet RT. Use of angiotensin II inhibitors in patients that develop encapsulating peritoneal sclerosis. Perit Dial Int 2010;30:656-9. [CrossRef]

18. Noh H, Ha H, Yu MR, Kim YO, Kim JH, Lee HB. Angiotensin II mediates high glucose-induced TGF-beta1 and fibronectin upregulation in HPMC through reactive oxygen species. Perit Dial Int 2005;25:38-47.

19. Dainese L, Cappai A, Biglioli P. Recurrent pericardial effusion after cardiac surgery: the use of colchicine after recalcitrant conventional therapy. J Cardiothorac Surg 2011;10;6:96.

20. Kershenobich D, Vargas F, Garcia-Tsao G, Perez Tamayo R, Gent M, Rojkind M. Colchicine in the treatment of cirrhosis of the liver. N Engl J Med 1988;318:1709-13. [CrossRef]

21. Kaplan MM, Alling DW, Zimmerman HJ, Wolfe HJ, Sepersky RA, Hirsch GS, et al. A prospective trial of colchicine for primary biliary cirrhosis. $N$ Engl J Med 1986;315:1448-54. [CrossRef]

22. Peters SG, McDougall JC, Douglas WW, Coles DT, DeRemee RA. Colchicine in the treatment of pulmonary fibrosis. Chest 1993;103:101-4. [CrossRef]

23. Lloberas N, Cruzado JM, Franquesa M, Herrero-Fresneda I, Torras J, Alperovich G, et al. Mammalian target of rapamycin pathway blockade slows progression of diabetic kidney disease in rats. J Am Soc Nephrol 2006;17:1395-404. [CrossRef]

24. Hartford CM, Ratain MJ. Rapamycin: something old, something new, sometimes borrowed and now renewed. Clin Pharmacol Ther 2007;82:381-8. [CrossRef]

25. Korfhagen TR, Le Cras TD, Davidson CR, Schmidt SM, Ikegami M, Whitsett JA, et al. Rapamycin prevents transforming growth factor-alpha-induced pulmonary fibrosis. Am J Respir Cell Mol Biol 2009;41:562-72. [CrossRef]

26. Temple S, Zaltzman J, Perl J. Development of encapsulating peritoneal sclerosis in a renal transplant recipient on sirolimus immunotherapy. Perit Dial Int 2010;30:475-7. [CrossRef]

27. Lloberas N, Cruzado JM, Franquesa M, Herrero-Fresneda I, Torras J, Alperovich G, et al. Mammalian target of rapamycin pathway blockade slows progression of diabetic kidney disease in rats. J Am Soc Nephrol 2006;17:1395-404. [CrossRef]

28. Kramer S, Wang-Rosenke Y, Scholl V, Binder E, Loof T, Khadzhynov D, et al. Low-dose mTOR inhibition by rapamycin attenuates progression in anti-thy1- induced chronic glomerulosclerosis of the rat. Am J Physiol Renal Physiol 2008;294:F440-9. [CrossRef]

29. Peker K, Inal A, Sayar I, Sahin M, Gullu H, Inal DG, et al. Prevention of intraabdominal adhesions by local and systemic administration of immunosuppressive drugs. Iran Red Crescent Med J 2013;15:e14148. [CrossRef]

30. Parsons CJ, Takashima M, Rippe RA. Molecular mechanisms of hepatic fibrogenesis. J Gastroenterol Hepatol 2007;22:79-84. [CrossRef] 